\title{
Functional connectivity of motor cortical network in patients with brachial plexus avulsion injury after contralateral cervical nerve transfer: a resting-state fMRI study
}

\author{
Aihong Yu ${ }^{1}$ - Shufeng Wang ${ }^{2} \cdot$ Xiaoguang Cheng ${ }^{1} \cdot$ Wei Liang $^{1} \cdot$ Rongjie Bai ${ }^{1}$. \\ Yunhao Xue ${ }^{2}$ Wenjun $\mathrm{Li}^{2}$
}

Received: 27 July 2016 / Accepted: 27 January 2017 /Published online: 24 February 2017

(C) The Author(s) 2017. This article is published with open access at Springerlink.com

\begin{abstract}
Introduction The purpose of this study is to assess the functional connectivity of the motor cortical network in patients with brachial plexus avulsion injury (BPAI) after contralateral C7 nerve transfer, using resting-state functional magnetic resonance imaging (RS-fMRI).

Methods Twelve patients with total brachial plexus root avulsion underwent RS-fMRI after contralateral C7 nerve transfer. Seventeen healthy volunteers were also included in this fMRI study as controls. The hand motor seed regions were defined as region of interests in the bilateral hemispheres. The seedbased functional connectivity was calculated in all the subjects. Differences in functional connectivity of the motor cortical network between patients and healthy controls were compared.

Results The inter-hemispheric functional connectivity of the M1 areas was increased in patients with BPAI compared with the controls. The inter-hemispheric functional connectivity between the supplementary motor areas was reduced bilaterally.

Conclusions The resting-state inter-hemispheric functional connectivity of the bilateral M1 areas is altered in patients after
\end{abstract}

Electronic supplementary material The online version of this article (doi:10.1007/s00234-017-1796-0) contains supplementary material, which is available to authorized users.

Aihong Yu

imaging2008@sina.com

1 Department of Radiology, Beijing Jishuitan Hospital, The 4th Medical College of Peking University, 31 Xinjiekou E Rd, Xicheng Qu, Beijing 100035, China

2 Department of Hand Surgery, Beijing Jishuitan Hospital, The 4th Medical College of Peking University, Beijing, China contralateral C7 nerve transfer, suggesting a functional reorganization of cerebral cortex.

Keywords Contralateral C7 nerve transfer · Brachial plexus avulsion injury $\cdot$ Functional connectivity $\cdot$ Resting state . Cerebral plasticity

\section{Introduction}

Brachial plexus avulsion injury (BPAI) is the most severe peripheral nerve injury and typically results in paralysis of the affected upper limb, which significantly reduces quality of life. Surgical restoration of hand function, especially finger flexion, is challenging in patients with total BPAI. Contralateral $\mathrm{C} 7$ nerve transfer to the median nerve via a long vascularized ulnar nerve graft is an effective procedure that was first developed by $\mathrm{Gu}$ et al. in clinical studies [1-4]. After contralateral C7 nerve transfer, the bilateral limbs of patients with BPAI share a single pyramidal pathway, descending from the cerebral cortex ipsilateral to the affected plexus, resulting in restoration of the affected arm function.

In early post-operative stages, the motor function recovery appeared only as bilateral associated movements. However, a few patients regained independent motor function of the affected wrist and fingers following long-term functional exercise [5]. The unique clinical phenomenon suggests extensive cortical reorganization in the bilateral motor cortex. However, the central mechanisms underlying motor plasticity after contralateral $\mathrm{C} 7$ nerve transfer remain unclear, although a few functional imaging studies showed intra-hemispheric and inter-hemispheric cortical plasticity in rats and humans [6-10]. However, the interactions of motor networks in the resting state after contralateral $\mathrm{C} 7$ nerve transfer have not yet been investigated. Resting-state functional magnetic 
resonance imaging (RS-fMRI) has been used to explore the inter-regional correlation in terms of functional connectivity or "intrinsic connectivity," which is thought to reflect the intrinsic functional architecture of the human brain [11-13]. This technique has been widely used to investigate functional reorganization in subjects suffering from central or peripheral nervous system disease [14-16].

In the present study, the functional connectivity of the motor cortical network in patients with BPAI after contralateral C7 nerve transfer has been assessed using RS-fMRI.

\section{Material and methods}

\section{Subjects}

The subjects included 12 patients with unilateral total BPAI due to traffic accidents ( 7 men and 5 women, mean age $26.2 \pm 9.1$ years, range $17-54$ years). On average, the interval between trauma and contralateral $\mathrm{C} 7$ transfer surgery was 3.5 months, ranging from 1 to 13 months. The average interval between contralateral C7 transfer surgery and functional MRI was 34.4 months, ranging from 18 to 48 months (Table 1). All the patients had complete avulsion of the five roots, and the muscle strength of finger and wrist flexion in all the patients was graded as M0 before contralateral C7 nerve transfer. The preliminary diagnosis of complete brachial plexus injury was based on detailed history, meticulous physical examination, and results using needle electromyography (EMG). All the patients were subjected to computed tomographic myelography (CTM) and MRI of brachial plexus. MRI of brachial plexus was acquired at two centers randomly to reduce travel time of the patients in the study. Acquisition parameters were adjusted to be as equal as possible between the two scanners at two centers, while still having near optimal settings for each system. Each patient underwent clinical evaluation for residual motor function and signs of associated neurological lesions. All the patients underwent surgical exploration and contralateral $\mathrm{C} 7$ nerve transfer via the modified pre-spinal route and direct coaptation of the contralateral $\mathrm{C} 7$ nerve with the lower trunk to restore finger flexion [3]. All the surgical interventions were performed by the same medical team at Beijing Jishuitan Hospital. The modified British Medical Research Council (MRC) muscle grading system [4] was used to evaluate the motor function after the patients regained finger flexion. The strength of finger flexion was tested with the wrist extended $20^{\circ}$ to $30^{\circ}$. Muscle strength was graded as poor (M0 to M2), fair (M2+ to M3), good (M3+ or M4-), or excellent (M4 to M5-). The muscle strength of finger and wrist flexion in all the patients was graded as M4.

No history of psychiatric or neurological abnormalities was found in any patient. The control group consisted of 17 agematched healthy volunteers (mean age $26.3 \pm 2.8$ years, range
21-30 years) with no history of psychiatric or neurological abnormalities. All the participants were right-handed. Handedness was determined using Peking University Hand Preference Inventory. Written informed consent was obtained from all subjects. The study protocol, amendments, and informed consent were reviewed and approved by the local institutional review boards.

\section{MR data acquisition}

MR imaging was performed using a 1.5-T MR scanner (Siemens Magnetom Espree, Germany). All the data were acquired using a standard quadrature birdcage head coil for both RF transmission and reception. Anatomical images were obtained from axial multi-slice SE T1-weighted images [TR $($ repetition time $)=500 \mathrm{~ms}$, TE $($ echo time $)=7.7 \mathrm{~ms}$, matrix size $256 \times 256$, FOV $230 \times 230 \mathrm{~mm}$, slice thickness $5 \mathrm{~mm}$ and gap $1.5 \mathrm{~mm}, 20$ slices]. Resting-state functional images were acquired using a whole-brain 3D echo-planar imaging (EPI) sequence [TR $2730 \mathrm{~ms}$, TE $45 \mathrm{~ms}$, flip angle $=90^{\circ}$, matrix $64 \times 64$, slice thickness $5 \mathrm{~mm}$, gap $1.5 \mathrm{~mm}$, FOV $230 \times 230 \mathrm{~mm}$, resolution $3.6 \times 3.6 \mathrm{~mm}$ in-plane], providing blood oxygenation level-dependent (BOLD) contrast. The resting run generated 180 whole-brain volumes. High-resolution, T1-weighted gradient echo 3D images (magnetization prepared rapid gradient echo imaging (MPRAGE)) were then acquired for coregistration $[\mathrm{TR} / \mathrm{TE}=1970 \mathrm{~ms} / 3.6 \mathrm{~ms}$, flip angle $=15^{\circ}$, slice plane sagittal, slice thickness $=1 \mathrm{~mm}$, gap $0.5 \mathrm{~mm}, \mathrm{FOV}=256 \times 256 \mathrm{~mm}$, matrix size $=192 \times 256,176$ slices].

During the resting fMRI session, the subjects were instructed to keep their eyes closed, to remain motionless, and not to think of anything in particular.

\section{Data preprocessing}

Resting-state fMRI data were pre-processed using previously described procedures [17]. The following steps were performed: slice timing and rigid body correction for head motion, data smoothing (6-mm full width at half maximum), lowpass temporal filtering, ventricular and white matter signal regression, normalization for global mean signal intensity across runs, and transformation of the data into a standard atlas space. All images were temporarily low-pass filtered $(0.01 \mathrm{~Hz}<$ frequency $<0.08 \mathrm{~Hz})$.

Whole-brain signal regression was also included in the processing stream, which improved the correction of motion-related artifacts [18]. All subjects included in this study met the quality control criterion of slice-based temporal signal-to-noise ratio $>100$.

The strength of functional correlation between the motor cortex (M1) and supplementary motor area (SMA) was quantified for each patient using hand motor seed regions 
Table 1 Patient demographics

\begin{tabular}{|c|c|c|c|c|c|c|}
\hline Case no. & Sex & Age (years) & Handedness & Lesions & Muscle grade & $\begin{array}{l}\text { Time course of fMRI } \\
\text { post-surgery (months) }\end{array}$ \\
\hline 1 & $\mathrm{~F}$ & 24 & $\mathrm{R}$ & $\mathrm{R}$ & M4 & 48 \\
\hline 2 & $\mathrm{~F}$ & 23 & $\mathrm{R}$ & $\mathrm{L}$ & M4 & 48 \\
\hline 3 & M & 23 & $\mathrm{R}$ & $\mathrm{R}$ & M4 & 24 \\
\hline 4 & M & 26 & $\mathrm{R}$ & $\mathrm{L}$ & M4 & 48 \\
\hline 5 & M & 17 & $\mathrm{R}$ & $\mathrm{R}$ & M4 & 36 \\
\hline 6 & M & 23 & $\mathrm{R}$ & $\mathrm{R}$ & M4 & 42 \\
\hline 7 & $\mathrm{~F}$ & 29 & $\mathrm{R}$ & $\mathrm{L}$ & M4 & 24 \\
\hline 8 & M & 39 & $\mathrm{R}$ & $\mathrm{R}$ & M4 & 18 \\
\hline 9 & $\mathrm{~F}$ & 22 & $\mathrm{R}$ & $\mathrm{L}$ & M4 & 36 \\
\hline 10 & $\mathrm{~F}$ & 54 & $\mathrm{R}$ & $\mathrm{R}$ & M4 & 27 \\
\hline 11 & M & 17 & $\mathrm{R}$ & $\mathrm{L}$ & M4 & 34 \\
\hline 12 & M & 24 & $\mathrm{R}$ & $\mathrm{L}$ & M4 & 28 \\
\hline
\end{tabular}

(Talairach-Tournoux coordinates $\pm 41,17,58$ ) defined from an independent study of actual hand movements [19]. The time course of each region of interest (ROI; radius $=6 \mathrm{~mm}$ ) was then extracted before functional connectivity analysis. After the ROIs were defined, Pearson's correlation coefficients between the time course of each ROI and that of every voxel in the whole brain (voxel-wise analysis) were calculated.

Correlation maps were computed for the two cerebral seed regions in each participant. The group-averaged, Fisher's $r$-to$z$ transformed correlation map was generated for each seed region. As a result, brain areas with significant connectivity to the ROIs within each group were obtained with a $p$ value $<0.005$ (uncorrected) at voxel level and a $p$ value $<0.05$ with an extent threshold of 27 voxels for the clusters (AlphaSim correction).

In order to test for crossed laterality, direct comparisons of the left and right cerebral seed regions were computed via arithmetic subtraction of the $z$ score correlation maps.

\section{Results}

In healthy volunteers, by placing an ROI in the left-hand or the right-hand motor seed regions, the cortical map showed significant functional connectivity between bilateral M1 areas and bilateral SMAs (Fig. 1 (a and b) and Table 2).

By placing an ROI in the hand area contralateral to the injured side or the intact side, significant functional connectivity was found between bilateral M1 areas and bilateral SMAs (Fig. 1 (c and d) and Table 2).

Compared with healthy volunteers, the inter-hemispheric functional connectivity of the M1 areas in the resting-state fMRI was increased in the patients with BPAI after contralateral C7 nerve. Inter-hemispheric functional connectivity between the two SMAs was reduced in the patients (Fig. 2 (a and b) and Table 3 ).

\section{Discussion}

As a non-invasive imaging modality, fMRI has revolutionized our understanding of functional networks and cerebral organization in both normal and pathological brains over the past several decades. Task-based functional imaging studies showed intra- and inter-hemispheric cortical plasticity in rats and humans following contralateral C7 nerve transfer for BPAI [6-10]. However, task-based fMRI scan is challenging for most BPAI patients who have to accomplish motor function of the affected wrist and fingers by bilateral associated movements, which result in movement artifacts. One of the important advantages of RS-fMRI is independence from functional tasks. In addition, the interactions of the motor networks can be investigated in the resting state after contralateral $\mathrm{C} 7$ nerve transfer.

In this study, alterations in the functional connectivity of motor cortex in BPAI following contralateral C7 nerve transfer were measured to investigate cortical reorganization. Our most important finding related to increased inter-hemispheric functional connectivity between the bilateral M1 areas in patients with BPAI after contralateral C7 nerve transfer compared with that of the controls. The strength of functional connectivity is consistent with the degree of spontaneous neuronal activity synchronization [11-13]. Functional connectivity reflects the intrinsic functional architecture of the human brain [11-13]. Changes in functional connectivity were found in subjects afflicted with central or peripheral nervous system disease [20-24]. Studies showed that resting-state inter-hemispheric functional connectivity and intrinsic horizontal functional connections of the primary motor areas were reduced following brachial plexus avulsion injury $[21,24]$. In the present study, the motor function of the affected wrist and fingers in patients with BPAI after C7 nerve transfer recovered with contralateral movements. The findings in this study suggest that the increased inter-hemispheric functional connectivity 


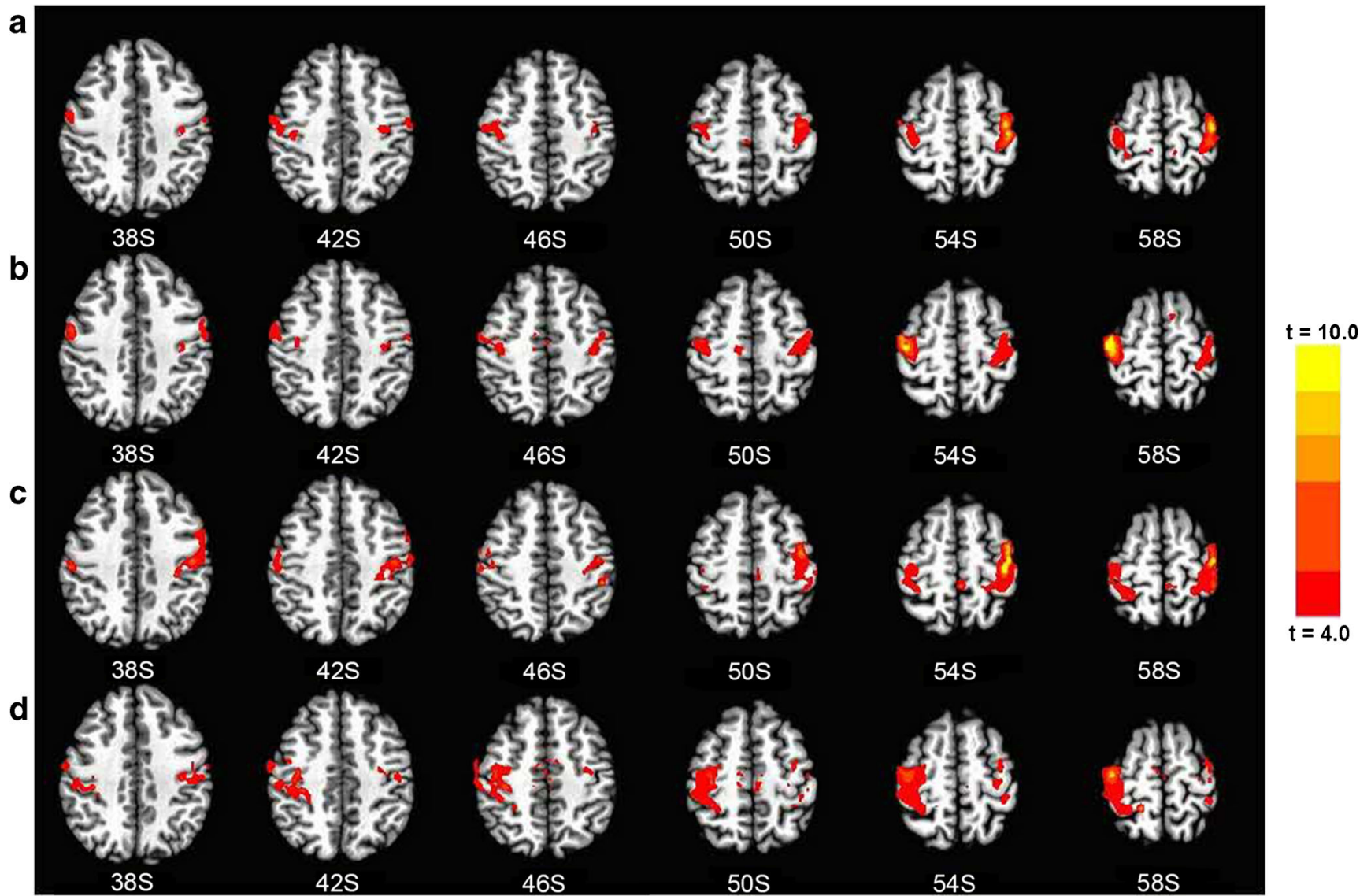

Fig. 1 Functional connectivity map, healthy controls vs. patients. An ROI in the left-hand motor seed regions $(a)$. An ROI in the right-hand injured side $(c)$. An ROI in the hand area contralateral to the intact side (d). Cortical map showed significant functional connectivity between bilateral M1 areas and bilateral SMAs

was related to the increased synchronization of the two primary motor areas and changes in intrinsic functional architecture of the patient's brain. This result suggests functional reorganization of the two primary motor areas in patients with BPAI after contralateral $\mathrm{C} 7$ nerve transfer.
The resting-state fMRI study in patients with BPAI after contralateral C7 nerve transfer was seldom reported, in contrast to task functional imaging studies. Accumulating evidence involving task functional imaging studies in patients with BPAI shows long-term plasticity between cortical
Table 2 Significant functional connectivity of healthy controls and patients

\begin{tabular}{|c|c|c|c|c|c|c|c|}
\hline \multirow[t]{2}{*}{ Group } & \multirow[t]{2}{*}{ ROIs } & \multirow[t]{2}{*}{ Regions } & \multicolumn{5}{|c|}{ Talairach-Tournoux coordinates } \\
\hline & & & Cluster size $\left(\mathrm{mm}^{3}\right)$ & $x$ & $y$ & $z$ & $t$ value \\
\hline \multirow[t]{6}{*}{ Control } & \multirow[t]{3}{*}{ L_Hand } & L_M1 & 8748 & -40 & -13 & 56 & 14.63 \\
\hline & & R_M1 & 8532 & 30 & -25 & 56 & 8.42 \\
\hline & & SMA & 1377 & -7 & -22 & 53 & 5.21 \\
\hline & \multirow[t]{3}{*}{ R_Hand } & L_M1 & 11,691 & -43 & -13 & 51 & 7.76 \\
\hline & & R_M1 & 11,313 & 40 & -20 & 56 & 10.21 \\
\hline & & SMA & 1269 & 13 & -22 & 51 & 5.75 \\
\hline \multirow[t]{4}{*}{ Patient } & \multirow[t]{2}{*}{ Injured side } & L_M1 & 10,017 & -40 & -16 & 56 & 15.06 \\
\hline & & R_M1 & 4860 & 26 & -43 & 59 & 10.98 \\
\hline & \multirow[t]{2}{*}{ Intact side } & L_M1 & 4185 & -25 & -34 & 62 & 4.47 \\
\hline & & R_M1 & 10,557 & 16 & -43 & 59 & 10.98 \\
\hline
\end{tabular}

$L$ left, $R$ right, $M 1$ the primary motor cortex, SMA supplementary motor area 


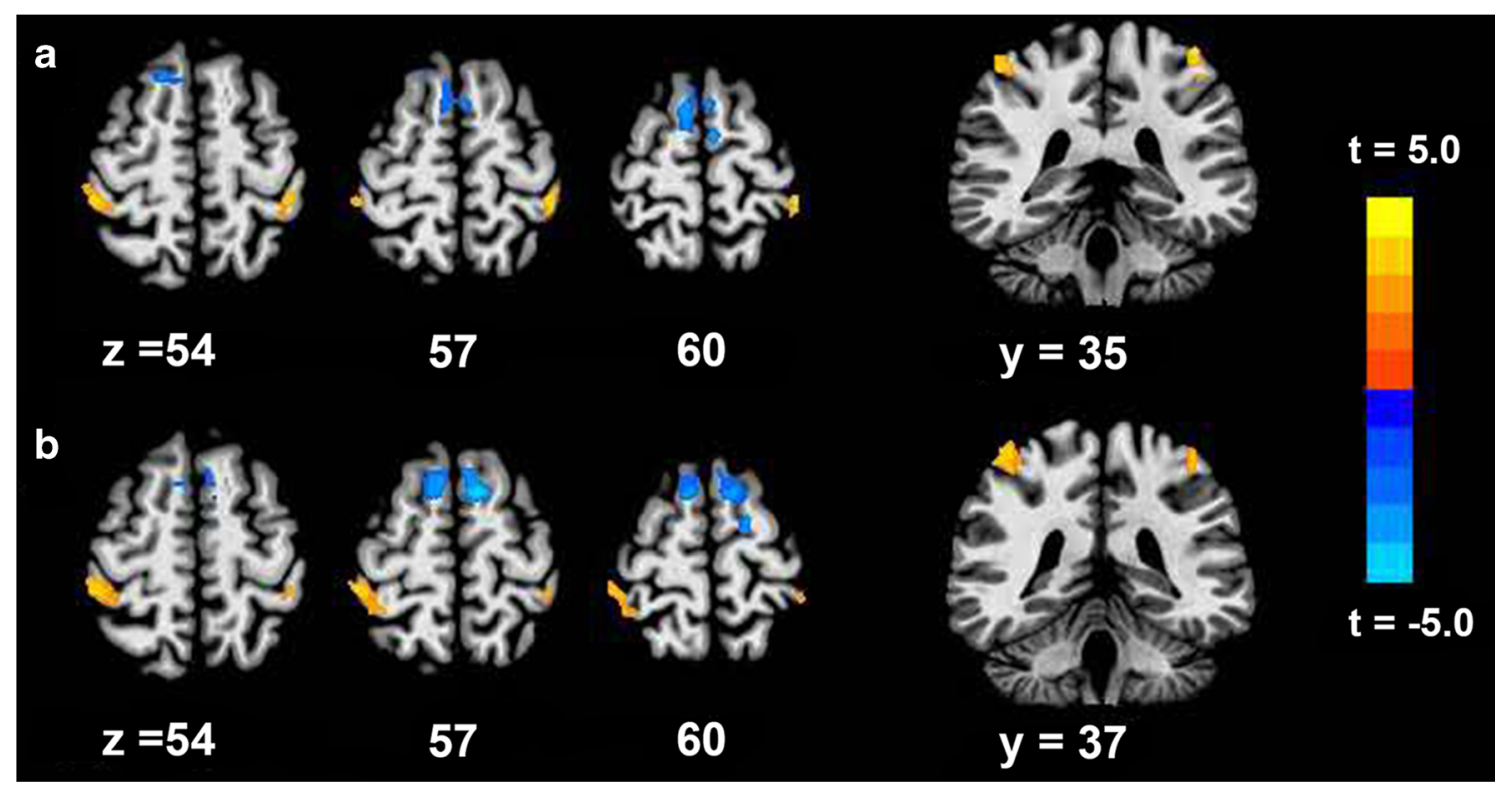

Fig. 2 An ROI in the hand area contralateral to the injured side $(a)$. An $\mathrm{ROI}$ in the hand area contralateral to the intact side $(b)$. Compared with healthy volunteers, patients showed an increase in inter-hemispheric

functional connectivity of the M1 areas in the resting-state fMRI and reduced functional connectivity between the two SMAs

hemispheres, in addition to cortical plasticity between neighboring regions in the same hemisphere [7, 25-27]. A study of long-term cortical remodeling in BPAI after contralateral C7 nerve transfer suggests that the motor control of the reinnervated limb was switched from the ipsilateral hemisphere of the affected plexus to the bilateral hemispheres and finally to the contralateral neural network activation [24], which is consistent with animal studies [9, 28]. The studies also suggest timedependent cortical reorganization. In the current study, the affected wrist and fingers in patients after contralateral C7 nerve transfer moved with the contralateral movements, and increased synchronization of the two primary motor areas of the brain occurred at specific clinical stages. We believe that functional connectivity may be altered when patients controlled the injured limb independently. RS-fMRI can be used to further elucidate the mechanisms of functional recovery in patients with contralateral C7 nerve transfer.

In this study, reduced inter-hemispheric functional connectivity occurred between the two SMAs of patients. A study with resting-state functional connectivity in patients with BPAI also discovered decreased functional connectivity between the SMA and multiple brain regions [29]. The SMA is thought to be a key structure and played a higher role in behavioral planning and execution, such as alternate motor plans, task switching, acquisition of new motor skills, and motor selection [30-32]. The motor function recovery is initiated with the primary motor function, compared with the poor restoration of higher and complex motor function.

The present study has several limitations. First, the study is a cross-sectional investigation. Longitudinal investigation including different pre- and post-surgical time points is important to study the dynamics of cortical plasticity in patients with BPAI. In this study, including the normal controls, controls from pre-surgical BPAI patients might provide more information, because functional connectivity change might be from C7 nerve transfer and post-surgical functional exercise and might also have existed before C7 nerve transfer. Second, the sample size was small since the incidence of contralateral
Table 3 Significant differences of functional connectivity between healthy controls and patients

\begin{tabular}{|c|c|c|c|c|c|c|c|}
\hline \multirow[t]{2}{*}{ Contrasts } & \multirow[t]{2}{*}{ ROIs } & \multirow[t]{2}{*}{ Regions } & \multicolumn{5}{|c|}{ Talairach-Tournoux coordinates } \\
\hline & & & Cluster size $\left(\mathrm{mm}^{3}\right)$ & $x$ & $y$ & $z$ & $t$ value \\
\hline \multirow[t]{4}{*}{ Patients $>$ controls } & \multirow[t]{2}{*}{ Injured side } & L_M1 & 1026 & -40 & -34 & 54 & 3.59 \\
\hline & & R_M1 & 1053 & 26 & -43 & 59 & 3.94 \\
\hline & \multirow[t]{2}{*}{ Intact side } & L_M1 & 1242 & -40 & -34 & 54 & 3.59 \\
\hline & & R_M1 & 1809 & 43 & -34 & 59 & 4.41 \\
\hline \multirow[t]{2}{*}{ Patients $<$ controls } & Injured side & SMA & 4266 & -4 & -7 & 62 & 4.97 \\
\hline & Intact side & SMA & 2430 & -7 & 7 & 56 & 4.65 \\
\hline
\end{tabular}

$L$ left, $R$ right, $M 1$ the primary motor cortex, SMA supplementary motor area 
C7 nerve transfer for BPAI is rare. Further, the small size was not conducive to a study based on age groups, although it is known that younger subjects may display additional neural plasticity. A longitudinal study with a larger number of patients is needed to investigate the changes in functional connectivity. We also intend to comprehensively evaluate the functional imaging results combined with muscle strength grading.

In conclusion, this study demonstrates that the resting-state inter-hemispheric functional connectivity of the bilateral M1 areas was altered in patients with BPAI following contralateral C7 nerve transfer, suggesting functional reorganization of the cerebral cortex.

\section{Compliance with ethical standards}

Funding This study was funded by the National Natural Science Foundation of China (Grant no: 81,271,558) and the Beijing Natural Science Foundation (Grant no: 7,132,061). The study was also funded by grants from the Beijing Bureau of 215 Program (No. 2013-3-033; 2009-02-03).

Conflict of interest The authors declare that they have no conflict of interest.

Ethical approval All procedures performed in the studies involving human participants were in accordance with the ethical standards of the institutional and/or national research committee and with the 1964 Helsinki Declaration and its later amendments or comparable ethical standards.

Informed consent Informed consent was obtained from all individual participants included in the study.

Open Access This article is distributed under the terms of the Creative Commons Attribution 4.0 International License (http:// creativecommons.org/licenses/by/4.0/), which permits unrestricted use, distribution, and reproduction in any medium, provided you give appropriate credit to the original author(s) and the source, provide a link to the Creative Commons license, and indicate if changes were made.

\section{References}

1. Gu YD, Chen DS, Zhang GM, Cheng XM, Xu JG, Zhang LY, Cai PQ, Chen L (1998) Long-term functional results of contralateral C7 transfer. J Reconstr Microsurg 14:57-59

2. Gu YD, Zhang GM, Chen DS, Yan JG, Cheng XM, Chen L (1992) Seventh cervical nerve root transfer from the contralateral healthy side for treatment of brachial plexus root avulsion. Journal of hand surgery (Edinburgh, Scotland) 17:518-521

3. Wang SF, Li PC, Xue YH, Yiu HW, Li YC, Wang HH (2013) Contralateral $\mathrm{C} 7$ nerve transfer with direct coaptation to restore lower trunk function after traumatic brachial plexus avulsion. J Bone Joint Surg Am 95(821-827):s821-s822

4. Terzis JK, Kokkalis ZT (2009) Selective contralateral c7 transfer in posttraumatic brachial plexus injuries: a report of 56 cases. Plast Reconstr Surg 123:927-938

5. Zuo CT, Hua XY, Guan YH, Xu WD, Xu JG, Gu YD (2010) Longrange plasticity between intact hemispheres after contralateral cervical nerve transfer in humans. J Neurosurg 113:133-140
6. Gao G-j, X-y F, Xu W-d, Y-d G, W-j T, G-x S, Li K, Li Y, Dao-ying $\mathrm{G}$ (2006) Functional reorganization of human motor cortex after unaffected side $\mathrm{C} 7$ nerve root transposition. Chinese Journal of Radiology 40:55-59

7. Beaulieu JY, Blustajn J, Teboul F, Baud P, De Schonen S, Thiebaud JB, Oberlin C (2006) Cerebral plasticity in crossed C7 grafts of the brachial plexus: an fMRI study. Microsurgery 26:303-310

8. Lou L, Shou T, Li Z, Li W, Gu Y (2006) Transhemispheric functional reorganization of the motor cortex induced by the peripheral contralateral nerve transfer to the injured arm. Neuroscience 138: $1225-1231$

9. Jiang S, Li ZY, Hua XY, Xu WD, Xu JG, Gu YD (2010) Reorganization in motor cortex after brachial plexus avulsion injury and repair with the contralateral $\mathrm{C} 7$ root transfer in rats. Microsurgery 30:314-320

10. Wang M, Li ZY, Xu WD, Hua XY, Xu JG, Gu YD (2010) Sensory restoration in cortical level after a contralateral $\mathrm{C} 7$ nerve transfer to an injured arm in rats. Neurosurgery 67:136-143 discussion 143

11. Nir Y, Mukamel R, Dinstein I, Privman E, Harel M, Fisch L, Gelbard-Sagiv H, Kipervasser S, Andelman F, Neufeld MY, Kramer U, Arieli A, Fried I, Malach R (2008) Interhemispheric correlations of slow spontaneous neuronal fluctuations revealed in human sensory cortex. Nat Neurosci 11:1100-1108

12. Lu H, Zuo Y, Gu H, Waltz JA, Zhan W, Scholl CA, Rea W, Yang Y, Stein EA (2007) Synchronized delta oscillations correlate with the resting-state functional MRI signal. Proc Natl Acad Sci U S A 104: 18265-18269

13. Biswal B, Yetkin FZ, Haughton VM, Hyde JS (1995) Functional connectivity in the motor cortex of resting human brain using echoplanar MRI. Magn Reson Med 34:537-541

14. Fox MD, Corbetta M, Snyder AZ, Vincent JL, Raichle ME (2006) Spontaneous neuronal activity distinguishes human dorsal and ventral attention systems. Proc Natl Acad Sci U S A 103:10046-10051

15. Vincent JL, Patel GH, Fox MD, Snyder AZ, Baker JT, Van Essen DC, Zempel JM, Snyder LH, Corbetta M, Raichle ME (2007) Intrinsic functional architecture in the anaesthetized monkey brain. Nature 447:83-86

16. Qiu TM, Chen L, Mao Y, Wu JS, Tang WJ, Hu SN, Zhou LF, Gu YD (2014) Sensorimotor cortical changes assessed with restingstate fMRI following total brachial plexus root avulsion. J Neurol Neurosurg Psychiatry 85:99-105

17. Van Dijk KR, Hedden T, Venkataraman A, Evans KC, Lazar SW, Buckner RL (2010) Intrinsic functional connectivity as a tool for human connectomics: theory, properties, and optimization. J Neurophysiol 103:297-321

18. Yan CG, Cheung B, Kelly C, Colcombe S, Craddock RC, Di Martino A, Li Q, Zuo XN, Castellanos FX, Milham MP (2013) A comprehensive assessment of regional variation in the impact of head micromovements on functional connectomics. NeuroImage 76:183-201

19. Lu J, Liu H, Zhang M, Wang D, Cao Y, Ma Q, Rong D, Wang X, Buckner RL, Li K (2011) Focal pontine lesions provide evidence that intrinsic functional connectivity reflects polysynaptic anatomical pathways. The Journal of neuroscience : the official journal of the Society for Neuroscience 31:15065-15071

20. Schilbach L, Hoffstaedter F, Muller V, Cieslik EC, GoyaMaldonado R, Trost S, Sorg C, Riedl V, Jardri R, Sommer I, Kogler L, Derntl B, Gruber O, Eickhoff SB (2016) Transdiagnostic commonalities and differences in resting state functional connectivity of the default mode network in schizophrenia and major depression. NeuroImage Clinical 10:326-335

21. Liu B, Li T, Tang WJ, Zhang JH, Sun HP, Xu WD, Liu HQ, Feng XY (2013) Changes of inter-hemispheric functional connectivity between motor cortices after brachial plexuses injury: a restingstate fMRI study. Neuroscience 243:33-39 
22. Klingner CM, Volk GF, Brodoehl S, Burmeister HP, Witte OW, Guntinas-Lichius O (2012) Time course of cortical plasticity after facial nerve palsy: a single-case study. Neurorehabil Neural Repair 26:197-203

23. Klingner CM, Volk GF, Maertin A, Brodoehl S, Burmeister HP, Guntinas-Lichius O, Witte OW (2011) Cortical reorganization in Bell's palsy. Restor Neurol Neurosci 29:203-214

24. Fraiman D, Miranda MF, Erthal F, Buur PF, Elschot M, Souza L, Rombouts SA, Schimmelpenninck CA, Norris DG, Malessy MJ, Galves A, Vargas CD (2016) Reduced functional connectivity within the primary motor cortex of patients with brachial plexus injury. Neuroimage Clin 12:277-284

25. Hua XY, Liu B, Qiu YQ, Tang WJ, Xu WD, Liu HQ, Xu JG, Gu YD (2013) Long-term ongoing cortical remodeling after contralateral C-7 nerve transfer. J Neurosurg 118:725-729

26. Sokki AM, Bhat DI, Devi BI (2012) Cortical reorganization following neurotization: a diffusion tensor imaging and functional magnetic resonance imaging study. Neurosurgery 70:1305-1311 discussion 1311

27. Yoshikawa T, Hayashi N, Tajiri Y, Satake Y, Ohtomo K (2012) Brain reorganization in patients with brachial plexus injury: a longitudinal functional MRI study. TheScientificWorldJOURNAL 2012:501751

28. Stephenson JB, Li R, Yan JG, Hyde J, Matloub H (2013) Transhemispheric cortical plasticity following contralateral C7 nerve transfer: a rat functional magnetic resonance imaging survival study. The Journal of hand surgery 38:478-487

29. Lu Y, Liu H, Hua X, Xu WD, Xu JG, Gu YD (2016) Supplementary motor cortical changes explored by resting-state functional connectivity in brachial plexus injury. World Neurosurg 88:300-305

30. Hiroshima S, Anei R, Murakami N, Kamada K (2014) Functional localization of the supplementary motor area. Neurol Med Chir 54: $511-520$

31. Kim JH, Lee JM, Jo HJ, Kim SH, Lee JH, Kim ST, Seo SW, Cox RW, Na DL, Kim SI, Saad ZS (2010) Defining functional SMA and pre-SMA subregions in human MFC using resting state fMRI: functional connectivity-based parcellation method. NeuroImage 49:2375-2386

32. Nachev P, Wydell H, O’Neill K, Husain M, Kennard C (2007) The role of the pre-supplementary motor area in the control of action. NeuroImage 36(Suppl 2):T155-T163 